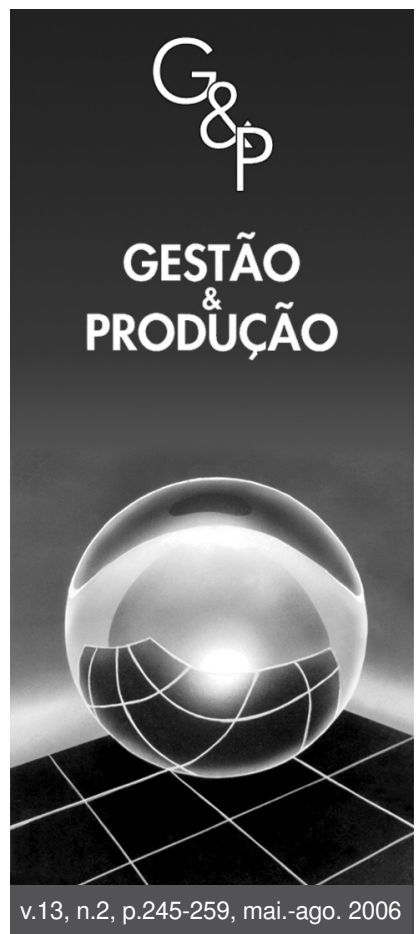

\title{
PROPOSTA DE UM MÉTODO PARA INTEGRAÇÃO ENTRE QFD E FMEA
}

\author{
José Márcio Ramos Fernandes \\ Marcelo Giroto Rebelato
}

Programa de Pós-Graduação em Engenharia de Produção e Sistemas - PUCPR, Rua Imaculada Conceição, 1155, CEP 80215-901, Curitiba, PR, e-mails: jose.fernandes@br.bosch.com,m.giroto@pucpr.br

\section{Resumo}

Nos dias atuais, dois métodos voltados ao planejamento da qualidade mostram reconhecimento mundial pela sua utilidade e pelos relatos de sucessos obtidos com seu uso: QFD (Quality Function Deployment), no desenvolvimento do produto e do processo; e FMEA (Failure Mode and Effects Analysis), na análise de falhas. Estes dois métodos, entretanto, são freqüentemente vistos como ferramentas sem inter-relação e sua integração, quando ocorre na prática, é tradicionalmente insuficiente e mal explorada. Neste contexto, este artigo tem o objetivo de propor um método para a integração entre QFD e FMEA. A abordagem proposta apresenta mudanças em ambos os métodos, visando incrementar a eficiência da integração e tornar mais clara a apresentação. Para uma melhor visualização do método proposto, um exemplo fictício de aplicação é apresentado.

Palavras-chave: QFD (Quality Function Deployment), FMEA (Failure Mode and Effects Analysis), método para integração QFD/FMEA.

\section{Introdução}

A gestão da qualidade, que pode ser vista ao mesmo tempo como uma função gerencial, uma disciplina acadêmica e uma área de pesquisa e desenvolvimento, vem passando, desde o início do século passado, por contínuos e gradativos aprimoramentos no tocante ao desenvolvimento e à aplicação de novos métodos gerenciais. Dentre os diversos métodos da qualidade criados nos últimos 40 anos, dois deles chamam a atenção pela utilidade reconhecida dentro das ações voltadas ao planejamento da qualidade, pela grande quantidade de trabalhos científicos que suscitaram e pelos inúmeros relatos de sucesso obtidos com seu uso: QFD (Quality Function Deployment) e FMEA (Failure Mode and Effetcs Analysis).

Em 1963, aproximadamente, durante a missão Apollo, a agência norte-americana NASA (National Aeronautics and Space Administration) desenvolveu um método para identificar, de forma sistemática, falhas potenciais em sistemas, processos ou serviços, identificar seus efeitos, suas causas e, a partir disso, definir ações para reduzir ou eliminar o risco associado a essas falhas. Esse método foi chamado de Análise de Modos e Efeitos de Falha (FMEA) (Puente et al., 2002). Mesmo tendo surgido em 1963, FMEA somente passou a ser utilizado de forma mais abrangente após 1977, quando a Ford Motors Company começou a utilizar o método na fabricação de automóveis (Gilchrist, 1993).

Em 1978, os professores japoneses Shigeru Mizuno e Yoji Akao desenvolveram o método chamado Quality Function Deployment ( $Q F D$ ), em português, Desdobramento da Função Qualidade, com a finalidade de integrar as necessidades expressas pelos clientes ao desenvolvimento de produtos e processos. $Q F D$ foi uma resposta 
dos acadêmicos a uma forte carência que existia, desde 1969, dentro do movimento Total Quality Control (TQC) relativamente à operacionalização do planejamento da qualidade (Lin, 1995; Akao, 1990).

Com frequiência, $Q F D$ e $F M E A$ são vistos como métodos totalmente separados e sem interface importante. Dessa forma isolada, todo o potencial de cada método não é explorado. Por outro lado, em algumas empresas, o método $Q F D$ tem sido utilizado como suporte para os primeiros estágios do desenvolvimento de produtos e processos, enquanto que o método $F M E A$ tem sua utilização na fase final desse desenvolvimento, objetivando a análise de falhas. Desse modo, a desejada complementaridade entre os dois métodos não é adequadamente aplicada. A prática da utilização conjunta de $Q F D$ e $F M E A$, quando ocorre, não enfoca objetivamente a análise das falhas potenciais e reais sobre todas as fases de desenvolvimento ("desdobramentos") de $Q F D$ (Ginn et al.,1998).

A falta de integração pode ser compreendida ao notarse que cada método foi criado ao seu tempo, por uma organização específica ou especialista distinto, que tinha um problema gerencial particular e o objetivo de saná-lo. Como resultado desses processos isolados de desenvolvimento, $Q F D$ e $F M E A$ não contêm interfaces previstas para aplicação conjunta.

O que é relevante, porém, é que as lacunas de integração atualmente existentes entre os métodos da qualidade dificultam a ação gerencial. Com efeito, as empresas que não conseguem visualizar esses "vazios de integração" e, ao mesmo tempo, não trabalham para repará-los, operam inevitavelmente um gerenciamento fragmentado (Keller, 2003).

Frente à problemática apresentada, este trabalho tem como objetivo principal propor um método de integração entre $Q F D$ e FMEA. Como objetivo complementar, algumas mudanças funcionais e de apresentação são propostas para ambos os métodos, visando tornar a integração mais clara e eficaz.

\section{Metodologia de desenvolvimento}

De acordo com Cervo e Bervian (2002), as pesquisas científicas podem ser classificadas pela sua natureza, sua forma de abordagem, pelo caráter dos objetivos e dos procedimentos técnicos adotados. Este trabalho é classificado, quanto à sua natureza, como aplicado, ou seja, os conhecimentos aqui gerados são aplicáveis em uma situação prática. Quanto à forma de abordagem, classifica-se este trabalho como qualitativo, pois as avaliações e discussões apresentadas são subjetivas e baseadas na interpretação dos fatos. Com respeito aos objetivos, estes podem ser classificados como exploratórios, porque, a partir da exploração do funcionamento, entradas e saídas de $Q F D$ e $F M E A$, propõe-se uma nova abordagem para sua integração. Em relação aos procedimentos técnicos para coleta de informações, o trabalho baseia-se em pesquisa bibliográfica.

Para o alcance dos objetivos traçados, seguiram-se as seguintes etapas de desenvolvimento:

a) Análise dos métodos $Q F D$ e $F M E A$ isoladamente - o objetivo nesta etapa foi estudar e compreender, em detalhe, cada método;

b) Determinação da integração entre os métodos - a partir da identificação e análise das "saídas" de $Q F D$ e "entradas" de FMEA, buscaram-se novas possibilidades de integração, chegando-se a uma proposta com maior grau de inter-relacionamento entre os métodos do que a abordagem tradicional; e

c) Desenvolvimento da funcionalidade para a interface com mudanças em $Q F D$ e $F M E A$ - visando conseguir melhor integração lógica, desenvolveu-se uma dinâmica operacional para $Q F D$ e FMEA diferente do mecanismo funcional original de cada método. Nesta etapa, analisou-se como $Q F D$ e $F M E A$ poderiam ser alterados para que a classificação das severidades em FMEA fosse balizada pelas importâncias relativas de $Q F D$, de modo a estabelecer uma lógica única e integrada de ação. Também se alterou a apresentação gráfica do método FMEA, objetivando-se maior clareza e menor redundância de informações.

Este artigo faz uma exposição de cada método de maneira muito sucinta para, em seguida, apresentar a integração tradicional entre eles. A partir disso, apresenta-se a nova forma de integração entre cada ciclo de $Q F D$ e $F M E A$. Em seguida, expõe-se a funcionalidade proposta da integração completa em dezenove etapas, detalhando-se a aplicação de cada etapa. Evidenciam-se e se justificam as alterações operacionais efetuadas em cada método. Por fim, desenvolve-se a aplicação do método proposto sobre um exemplo fictício para tornar o processo integrado mais claro para o leitor.

\section{0 método QFD}

$Q F D$ foi um método criado para operacionalizar o processo de planejamento da qualidade na forma de uma série de relações causa e efeito, operacionalizadas por meio de matrizes. Em cada ciclo de $Q F D$, relacionamse as necessidades da qualidade ("o que se espera") com os requisitos da qualidade ("como se pretende fazer"), identificando-se, na matriz de relações, a intensidade do relacionamento entre eles por meio de "símbolos de relações" (Figura 1). Cada símbolo tem um peso numérico representando esta intensidade.

A importância relativa é uma classificação (priorização) de cada necessidade da qualidade (“o que se espera"). Essas necessidades são ponderadas segundo o grau 
de importância para o cliente, atribuindo-se a cada uma um valor numérico. Na parte superior da figura, identificam-se os relacionamentos entre os requisitos da qualida-

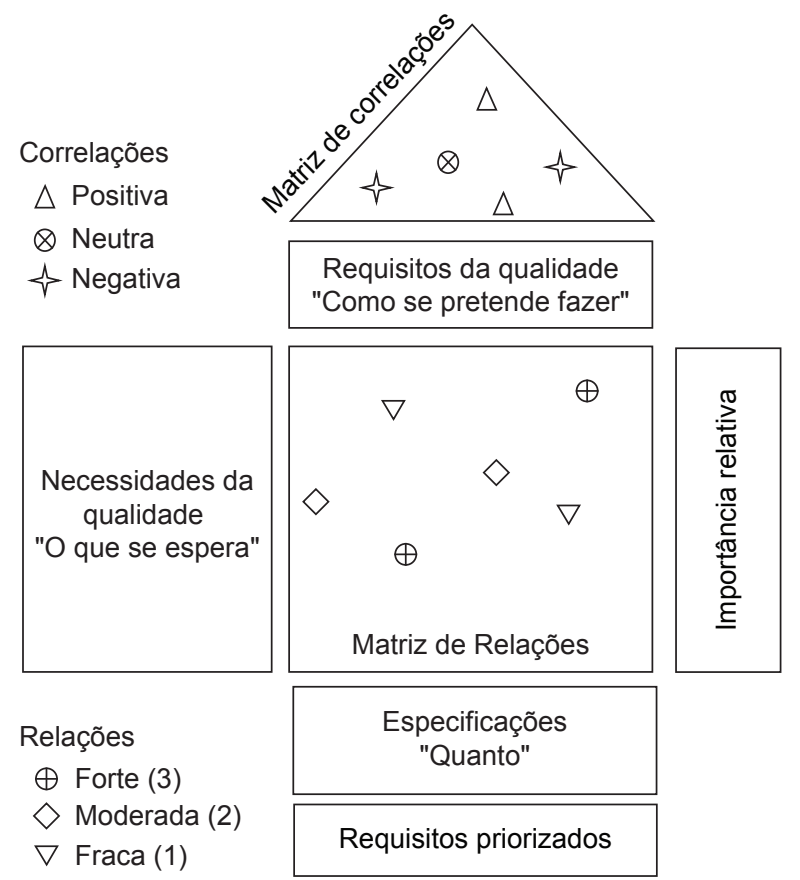

Figura 1. Representação simplificada do método $Q F D$. Fonte: adaptado de Berk e Berk (1997, p. 205). de (matriz de correlações). Estes relacionamentos identificam o grau de correlação entre os requisitos, auxiliando na priorização e identificação de "soluções de compromisso" entre eles. As especificações do projeto ("quanto") representam uma quantificação de cada requisito da qualidade. Os requisitos priorizados são calculados pela multiplicação do peso atribuído ao símbolo de relações (forte, moderado, fraco) pelo grau de importância relativa (Berk e Berk, 1997).

Existem diversas abordagens para o desenvolvimento de $Q F D$. Suas diferenças derivam da amplitude da aplicação e do uso de recursos de apoio. A abordagem mais conhecida é a "das quatro fases" (Guazzi, 1999). As quatro fases são, conforme Sullivan (1986) (Figura 2): 1) planejamento do produto - que transforma ou traduz "voz do cliente" em requisitos do produto; 2) desdobramento das partes - que transforma as características do produto em requisitos dos componentes; 3) planejamento do processo - que transforma as características dos componentes em requisitos do processo; e 4) planejamento da produção - que transforma as características do processo em requisitos da produção.

\section{O método FMEA}

Conforme Puente et al. (2002), o método FMEA é útil para identificar as falhas atuais e potenciais e seus efeitos em sistemas e processos para definir ações que visem re-

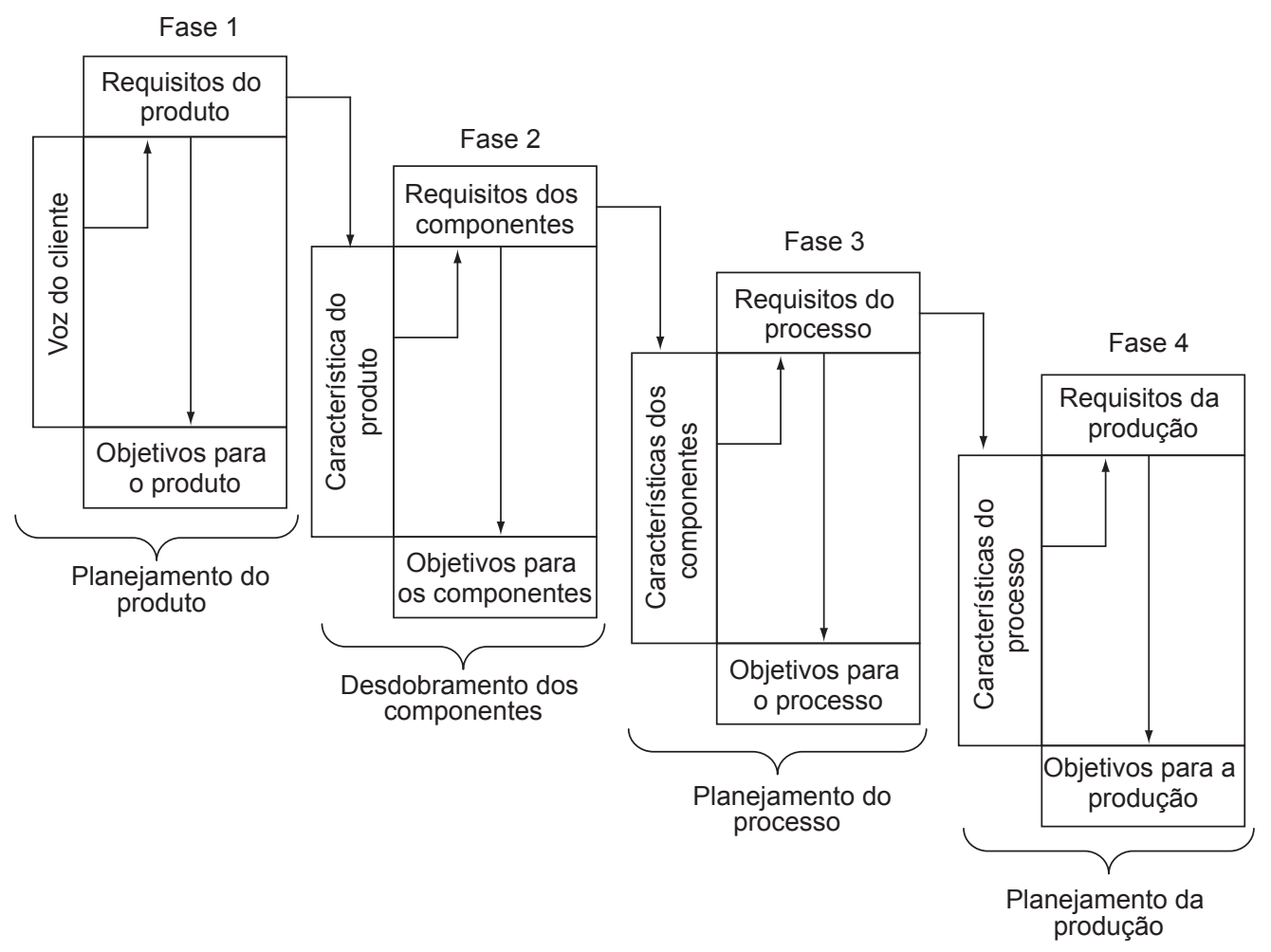

Figura 2. Abordagem "das quatro fases" para desenvolvimento de $Q F D$. 
duzir ou eliminar o risco associado a cada falha. FMEA avalia a severidade de cada falha relativamente ao impacto causado aos clientes, sua probabilidade de ocorrência e de detecção antes de chegarem às mãos dos clientes. Com base nestes três elementos, severidade, ocorrência e detecção, o método $F M E A$ leva à priorização de quais modos de falha acarretam os maiores riscos ao cliente e que, portanto, merecem atenção. Para a avaliação da severidade, parece haver concordância de que esta deva ser realizada a partir do efeito da falha. Porém, para avaliação da ocorrência e detecção, não se observa consenso entre os autores (Tabela 1).

As etapas para a execução de FMEA são: 1) identificar modos de falha conhecidos e potenciais; 2) identificar os efeitos de cada modo de falha e a sua respectiva severidade; 3) identificar as causas possíveis para cada modo de falha e a sua probabilidade de ocorrência; 4) identificar os meios de detecção do modo de falha e sua probabilidade de detecção; e 5) avaliar o potencial de risco de cada modo de falha e definir medidas para sua eliminação ou redução. Isto é conseguido por ações que aumentem a probabilidade de detecção ou reduzam a probabilidade de ocorrência da falha. A severidade é um índice que não pode ser reduzido ou eliminado, pois depende apenas do nível de transtorno que o efeito da falha trás ao cliente. Para determinar-se o risco associado a cada modo de falha, multiplica-se a pontuação da severidade (S) pela ocorrência (O) e pela detecção (D). Para classificar os riscos, pode-se ter, por exemplo, uma escala que vai de 1 a 1000 pontos, sendo 1 uma baixíssimo risco e 1000 um risco crítico ao cliente.

Segundo Stamatis (2003), existem três tipos principais de FMEA: a) FMEA de sistema; b) FMEA de produto; e c) FMEA de processo. FMEA de sistema (ou conceito) é utilizado para avaliar as falhas em sistemas nos estágios iniciais de conceituação e projeto. Enfoca as falhas do sistema em relação às suas funcionalidades e no atendimento das expectativas dos clientes, ou seja, está diretamente ligado à percepção do cliente em relação ao sistema. FMEA de produto é utilizado para avaliar possíveis falhas no projeto do produto antes da sua liberação para a manufatura. Enfoca as falhas do projeto em relação ao cumprimento dos objetivos definidos para cada uma de suas características e está diretamente ligado à capacidade do projeto em atender aos objetivos pré-definidos. FMEA de produto define necessidade de alterações no projeto do produto, estabelece prioridades para as ações de melhoria, auxilia na definição de testes e validação do produto, na identificação de características críticas e na avaliação dos requisitos e alternativas do projeto. FMEA de processo é utilizado para avaliar as falhas em processos antes da sua liberação para produção. Enfoca as falhas do processo em relação ao cumprimento dos seus objetivos pré-definidos e está diretamente ligado à capacidade do processo em cumprir esses objetivos. FMEA de processo define necessidades de alterações no processo, estabelece prioridades para as ações de melhoria, auxilia na execução do plano de controle do processo e na análise dos processos de manufatura e montagem.

\section{A integração tradicional entre QFD e FMEA}

Notadamente, tanto $Q F D$ quanto $F M E A$ visam verificar a percepção do cliente em relação às funções do produto. Ambos os métodos usam relações causa-efeito como eixo de análise e desenvolvimento, ambos prevêem a priorização das funções críticas ao cliente e ambos requerem um time multifuncional para serem executados. Porém, enquanto $Q F D$ enfoca a satisfação e o desempenho do produto em relação ao cliente, FMEA, por sua vez, enfoca a análise dos riscos atuais e potenciais de falha de cada função do produto (ou do processo ou do sistema), ou seja, objetiva "manter" as qualidades básicas do produto, visando atingir o nível esperado de qualidade.

Nas empresas, o método $Q F D$ é comumente executado em dois ciclos: 1) desdobramento das necessidades dos clientes em requisitos de produto; e 2) desdobramento dos requisitos do produto em requisitos de projeto. Aliado a isso, tradicionalmente, FMEAs de sistema e de controle de processos são muito pouco utilizados pelas empresas. Uma das razões para isso é o fato de não haver essa exigência particular de aplicação por parte das principais normas da qualidade. Por exemplo, as normas uti-

Tabela 1. Diferentes pontos de vista para avaliação da severidade, ocorrência e detecção.

\begin{tabular}{lcll}
\hline \multicolumn{1}{c}{ Fonte } & Severidade & Ocorrência & Detecção \\
\hline ECSS-Q-30-02 A (2001) & Efeito & Modo & Modo \\
Helman (1995) & Efeito & Causa & Modo/Efeito \\
Pinto e Xavier (2001) & Efeito & Modo & Modo \\
Layzell e Ledbetter (1998) & Efeito & Modo & Causa \\
MIL-STD-1629 A (2005) & Efeito & Modo & Modo \\
Palady (1997) & Efeito & Modo/Causa & Modo/Causa \\
Chrysler et al. (1998) & Efeito & Causa & Modo/Causa \\
\hline
\end{tabular}


lizadas na cadeia produtiva da indústria automotiva, QS 9000 e ISO/TS 16949, exigem apenas o desenvolvimento de FMEAs de produto e de processo. Desse modo, o que normalmente se observa são estes dois tipos de FMEA conjugados ao método $Q F D$ nos ciclos de projeto de produto e projeto de processo, respectivamente (Figura 3). Conforme a figura, não se observa a aplicação de $F M E A$ sobre as necessidades dos clientes, apenas sobre os requisitos do produto e do processo (Fernandes, 2005).

\section{0 método de integração proposto}

Uma das "saídas" básicas de $Q F D$ são os requisitos priorizados. Tanto requisitos do cliente, do produto e do processo, ou seja, para cada ciclo de $Q F D$ tem-se uma priorização dos requisitos, como resultado (Terninko, 1997). Por outro lado, FMEA tem como entrada os requisitos do cliente, do produto e do processo e informações sobre a importância relativa de cada uma das funções (Palady, 1997). Pode-se, então, obter as entradas de $F M E A$ utilizando as saídas de todos os ciclos de QFD. FMEA integrado a $Q F D$ passa a ter seus modos de falha ligados diretamente aos requisitos de $Q F D$ (Stamatis, 2003). Dessa forma, o melhor uso com FMEA poderia se dar com sua aplicação na fase de conceito e início do desenvolvimento do produto, pois, assim, poder-se-ia garantir, junto com o $Q F D$, o desdobramento da voz do cliente até os níveis de produto e processo (Ginn et al., 1998).
$\mathrm{Na}$ abordagem proposta, conforme a Figura 4, o método $Q F D$ é readaptado de modo a englobar quatro ciclos de relações causa e efeito. Esta adaptação é realizada com base na abordagem de $Q F D$ "das quatro fases", porém traz modificações. Na abordagem "das quatro fases", os

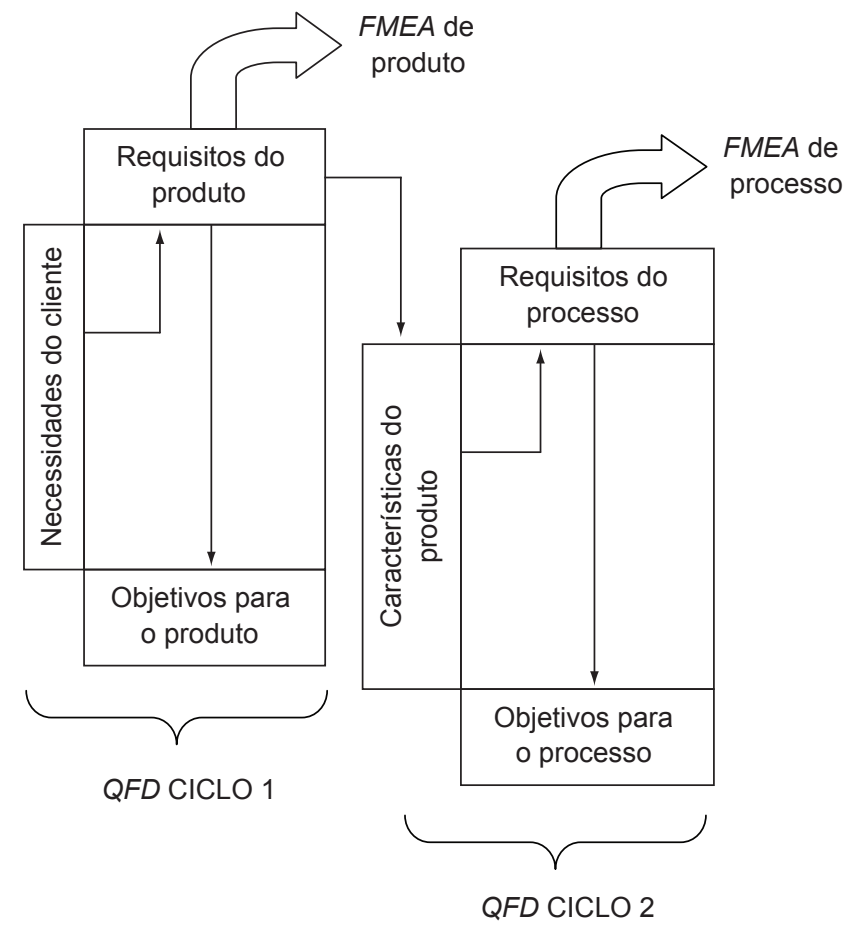

Figura 3. Integração tradicional $Q F D / F M E A$.

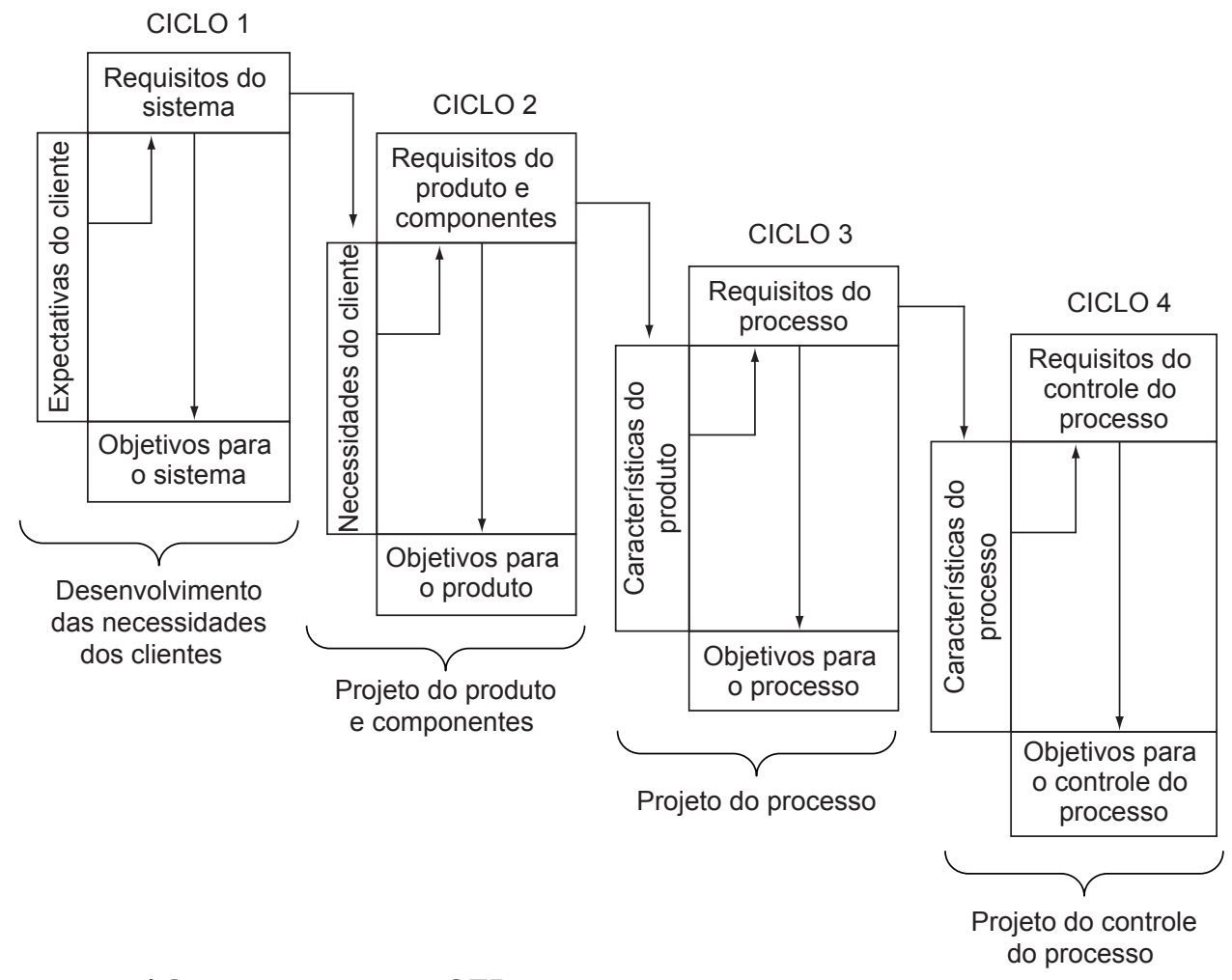

Figura 4. Os quatro ciclos propostos para $Q F D$. 
requisitos do produto são desenvolvidos diretamente por uma única matriz (fase 1), a partir das necessidades dos clientes. No método proposto, isto é feito em duas partes: primeiro, desdobram-se as expectativas dos clientes em requisitos do sistema (ciclo 1) e, em seguida, desdobram-se os requisitos do sistema em requisitos do produto (ciclo 2). Esta mudança tem como objetivo tornar a definição dos requisitos do produto mais pormenorizada, partindo-se das necessidades mais básicas dos clientes e chegando-se ao que o sistema precisa conter para satisfazê-las. Em seguida, a partir dos requisitos do sistema, chega-se aos requisitos do produto. Outra mudança está nas fases 2 e 3 , "projeto do produto" e "projeto dos componentes", respectivamente, que aqui são aglutinadas em um único ciclo (ciclo 2 - projeto do produto e componentes), por ser perfeitamente factível, a menos que o grau de complexidade do produto seja muito alto. Neste caso, pode-se perfeitamente manter o desdobramento original em duas fases.

Dessa forma, os quatro ciclos $Q F D$ propostos são: 1) desenvolvimento das necessidades dos clientes - que transforma as expectativas verbalizadas pelos clientes em requisitos que o sistema deve conter, ou seja, traduz os desejos expressos em "necessidades" exigidas para o "sistema produto"; 2) projeto do produto e componentes - que transforma as necessidades exigidas para o sistema em requisitos do produto e dos componentes; 3) projeto do processo - que transforma as características do produto e dos componentes em requisitos do processo, ou seja, estabelece os processos necessários e seus parâmetros; e 4) projeto do controle do processo - que transforma as características de cada processo em requisitos de controle, ou seja, estabelece os meios, mecanismos e métodos para o controle dos processos.

No método aqui delineado, todos os quatro ciclos de $Q F D$ apresentados na Figura 4 integram-se a FMEA (Figura 5).

O método proposto é desenvolvido por meio de dezenove etapas enumeradas e apresentadas na Figura 6: 1) desdobramento das expectativas dos clientes em requisitos do sistema; 2) avaliação dos modos de falhas nas expectativas; 3) determinação das causas e avaliação dos ricos de cada modo de falha; 4) planejamento de medidas na detecção e/ ou na ocorrência para redução dos riscos; 5) avaliação dos modos de falha nos requisitos do sistema; 6) determinação das causas e avaliação dos ricos de cada modo de falha; 7) planejamento de medidas na detecção e/ou na ocorrência;

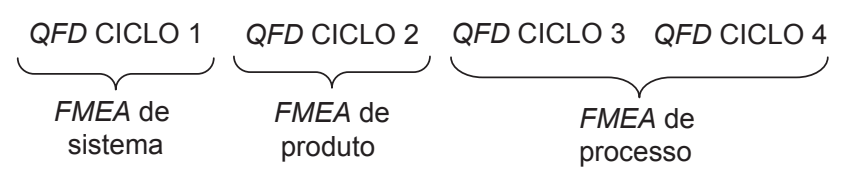

Figura 5. Integração $Q F D / F M E A$ proposta.
8) desdobramento dos requisitos do sistema em requisitos do produto e componentes; 9) avaliação dos modos de falha nos requisitos do produto e componentes; 10) determinação das causas e avaliação dos riscos de cada modo de falha; 11) planejamento de medidas na detecção e/ou na ocorrência; 12) desdobramento dos requisitos do produto e componentes em requisitos de processo; 13) avaliação dos modos de falha nos requisitos do processo; 14) determinação das causas e avaliação dos ricos de cada modo de falha; 15) planejamento de medidas na detecção e/ou na ocorrência; 16) desdobramento dos requisitos do processo em requisitos do controle do processo; 17) avaliação dos modos de falha nos requisitos de controle do processo; 18) determinação das causas e avaliação dos ricos de cada modo de falha; e 19) planejamento de medidas na detecção e/ou na ocorrência.

No método proposto, $Q F D$ apresenta uma importante alteração em sua operacionalização. Ela se dá na primeira matriz $Q F D$ (primeiro ciclo) com a ponderação das expectativas dos clientes que deverá ser realizada por meio de uma tabela de severidades, tal qual utilizada no método $F M E A$. Esta mudança tem o objetivo de tornar consistente a aplicação de $Q F D$ e $F M E A$ por meio da ponderação "dos atributos importantes para o produto" (as expectativas em $Q F D$ ) por uma tabela de severidades (que pondera a gravidade da falha em FMEA). Em outras palavras, a importância de cada expectativa será julgada pela classificação do impacto (severidade) do seu "não atendimento".

Nas demais matrizes $Q F D$ (ciclos 2 a 4), o peso de cada necessidade não mais será dado pela tabela de severidades, mas pela importância relativa (calculada) dos requisitos nas matrizes anteriores. Dessa forma, transportam-se as importâncias relativas de cada requisito da matriz 1, por exemplo, para a matriz 2, e assim sucessivamente. Na matriz 2 essas importâncias relativas serão os pesos das necessidades.

Há, porém, alterações mais significativas em FMEA. Com o uso tradicional de FMEA, o transtorno causado por cada modo de falha no cliente (a severidade da falha) é avaliado simplesmente com base no efeito da falha por meio da experiência do time de execução e pontuada por uma tabela de severidades. Na integração aqui proposta, as aplicações de FMEA "acopladas" aos ciclos $Q F D$ terão as severidades das falhas dadas automaticamente pelas importâncias relativas (calculadas) para os requisitos de cada desdobramento $Q F D$.

O conceito tradicional de FMEA apresenta algumas particularidades que dificultam a sua utilização. Uma delas é o fato de que, quando há uma ação atuando na detecção da falha (como "controle atual"), o formulário tradicional de FMEA obriga que esta ação seja repetida diversas vezes, pois é comum a ação de detecção estar relacionada ao modo de falha e não a uma causa específica. 


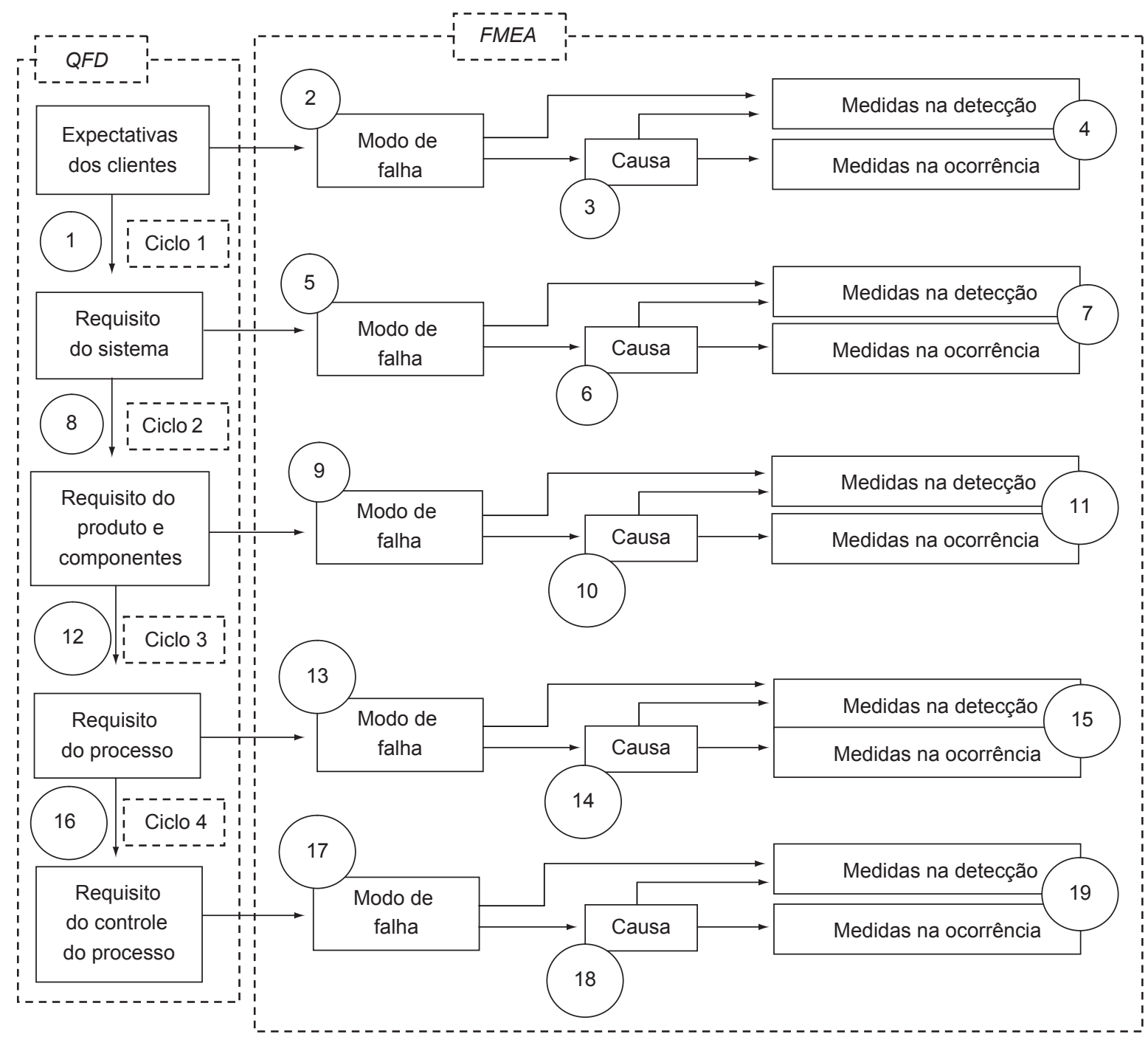

Figura 6. Método de integração proposto.

Como dentro de cada modo de falha podem existir várias causas possíveis, é necessário repetir as mesmas ações de detecção enquanto se estiver explorando aquele modo de falha. Isto gera trabalho (enfadonho) adicional e dificulta a atualização de $F M E A$.

$\mathrm{Na}$ abordagem proposta para $F M E A$, o formulário tradicional é substituído por uma apresentação em forma de árvore que se ramifica com cada necessidade ou requisito de $Q F D$ ligado ao modo de falha, às causas, às medidas concluídas e às medidas planejadas. Podendo, estas duas últimas, conter ações sobre a detecção ou sobre a ocorrência da falha. Desse modo, as ações sobre a detecção são apresentadas visualmente num formato diferenciado, evitando o problema de redundância gráfica.

Outro fato adverso é que o conceito tradicional de FMEA gera uma grande confusão em relação às informações dos controles atuais, ações recomendadas e ações tomadas, pois, quando se tem FMEA como "ferramenta viva", as ações recomendadas tornam-se controles atuais. Além disso, não se pode identificar facilmente se os controles atuais atuam sobre a detecção ou sobre a ocorrência da falha. Na abordagem proposta, os controles atuais são registrados na forma de "ações implantadas" em uma representação clara visual que, por meio de símbolos prédefinidos, evita este tipo de dúvida.

No conceito proposto, cada medida a ser implantada já está associada à sua futura classificação de ocorrência ou detecção, ou seja, há a possibilidade da estimativa da redução do risco, antes da implementação da ação, o que não é possível visualizar no formulário tradicional. Todas estas alterações ficarão mais claras com o exemplo apresentado adiante.

Observa-se, pela Figura 6, que as medidas tomadas na tentativa de diminuir a probabilidade de ocorrência das falhas estão ligadas diretamente à causa da falha, pois é sobre as causas que estas devem atuar. Já as medidas to- 
madas na tentativa de aumentar a probabilidade de detecção estão ligadas tanto à causa quanto ao modo de falha, pois é sobre estes dois que as medidas de detecção devem atuar. A severidade é um índice que não pode ser alterado diretamente, pois é classificado (avaliado) por meio do efeito da falha, e não se atua sobre o efeito. Adota-se, assim, o padrão de operação de $F M E A$ conforme a norma QS 9000 (Chrysler et al., 1998). Não há nada de absolutamente especial nesta adoção. Foi necessário eleger e estabelecer um padrão de operação em $F M E A$, e o padrão da norma citada é bastante utilizado pelas indústrias, especialmente as da cadeia automobilística.

\section{Exemplo fictício de aplicação do método proposto}

Para exemplificar a operacionalidade da integração proposta, tomar-se-á uma lâmpada incandescente num exemplo fictício. O produto e o processo serão simplificados de forma a tornar o exemplo mais didático. $\mathrm{O}$ produto está representado na Figura 7 e sua estrutura de componentes está representada na Figura 8.

Inicia-se a integração proposta (etapa 1) classificando-se as expectativas dos clientes com relação à lâmpada conforme sua importância. Para esta classificação, utiliza-se uma tabela de severidades de FMEA, definindo-se o "peso" de cada uma das necessidades. Para esta tabela, propõe-se uma simplificação da orientação contida no manual de FMEA da norma QS 9000 (Chrysler et al., 1998), apresentada na Tabela 2. No método $Q F D$ tradicional, utiliza-se uma tabela diferenciada, porém a integração $Q F D / F M E A$ traz vantagens na utilização da tabela de severidades neste ponto (e apenas neste), pois a avaliação do efeito da falha em todos os requisitos passa a "sincronizar-se", de maneira indireta, ao não atendimento da expectativa em $Q F D$, como poderá ser percebido.

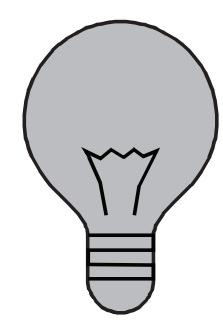

Figura 7. Lâmpada incandescente.

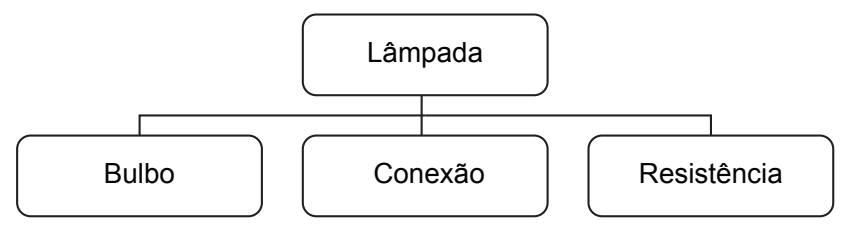

Figura 8. Estrutura de componentes da lâmpada.
Ainda na etapa 1 , devem ser definidos quais são os requisitos necessários ao sistema para atender a cada uma das expectativas do cliente. O desenvolvimento da matriz de correlações de $Q F D$ não será exposto, por simplificação. Fica implícito que este desenvolvimento é aplicado normalmente (conforme previsto em $Q F D$ ) dentro das etapas $1,8,12$ e 16 . Com os requisitos do sistema definidos, estes são relacionados com as expectativas, atribuindo-se "notas" (índices) conforme a intensidade da relação entre cada expectativa e cada requisito. Para isso, utiliza-se a Tabela 3. Reproduz-se, na Tabela 4, a matriz de $Q F D$ resultante até este ponto. A classificação das importâncias de cada expectativa (por meio da tabela de severidades) será indicada como "pesos" nesta matriz.

Tabela 2. Tabela para avaliação da severidade.

\begin{tabular}{clc}
\hline $\begin{array}{c}\text { Importância da } \\
\text { necessidade }\end{array}$ & \multicolumn{1}{c}{ Critério } & Severidade \\
\hline Muito alta & $\begin{array}{l}\text { Necessidade em relação à } \\
\text { segurança do usuário. }\end{array}$ & 10 \\
Alta & $\begin{array}{l}\text { Necessidade relacionada às } \\
\text { funções primárias do produ- } \\
\text { to ou serviço. }\end{array}$ & 8 \\
Moderada & $\begin{array}{l}\text { Necessidade relacionada à } \\
\text { funções secundárias porém, } \\
\text { relevantes ao cliente. } \\
\text { Baixa }\end{array}$ & $\begin{array}{l}\text { Necessidade relacionada à } \\
\text { funções secundárias porém, } \\
\text { pouco relevantes ao cliente. } \\
\text { Necessidade relacionada à } \\
\text { funções secundárias porém, } \\
\text { irrelevantes ao cliente. }\end{array}$ \\
\hline
\end{tabular}

Tabela 3. Tabela para avaliação de relações.

\begin{tabular}{llc}
\hline Relação & \multicolumn{1}{c}{ Critério } & Índice \\
\hline Muito & $\begin{array}{l}\text { A necessidade é diretamente impactada } \\
\text { Forte }\end{array}$ & 5 \\
& $\begin{array}{l}\text { impacta em total não atendimento da ne- } \\
\text { cessidade. }\end{array}$ & \\
Forte & $\begin{array}{l}\text { A necessidade é diretamente impactada } \\
\text { pelo requisito e o não atendimento deste }\end{array}$ & 3 \\
& $\begin{array}{l}\text { impacta em parcial não atendimento da } \\
\text { necessidade. }\end{array}$ & \\
Média & $\begin{array}{l}\text { A necessidade é impactada pelo requisito, } \\
\text { porém não atendimento desde tem impacto }\end{array}$ & 2 \\
& $\begin{array}{l}\text { pouco relevante no atendimento da neces- } \\
\text { sidade. }\end{array}$ & \\
Fraca & $\begin{array}{l}\text { A necessidade é fracamente impactada } \\
\text { pelo requisito e o não atendimento deste }\end{array}$ & 1 \\
& $\begin{array}{l}\text { não tem impacto relevante no atendimento } \\
\text { da necessidade. }\end{array}$ & \\
A necessidade não é impactada pelo requi- & 0 \\
sito, o não atendimento deste não tem im- & \\
pacto no atendimento da necessidade &
\end{tabular}


Tabela 4. Matriz de relações "Expectativa do Cliente x Requisitos do Sistema".

\begin{tabular}{lcccccc}
\hline \multicolumn{1}{c}{ Necessidades } & Pesos & $\begin{array}{c}\text { Filamento } \\
\text { adequado com } \\
\text { material especial }\end{array}$ & $\begin{array}{c}\text { Gás com nova } \\
\text { mistura }\end{array}$ & $\begin{array}{c}\text { Requisitos } \\
\text { Bulbo resistente }\end{array}$ & $\begin{array}{c}\text { Luminosidade } \\
\text { adequada }\end{array}$ & $\begin{array}{c}\text { Projeto que evite } \\
\text { riscos }\end{array}$ \\
\hline Iluminar ambiente & 8 & 5 & 5 & 0 & 5 & 0 \\
Baixo custo & 8 & 3 & 2 & 3 & 3 & 3 \\
Baixo consumo de energia & 6 & 5 & 2 & 0 & 3 & 0 \\
Iluminação agradável & 7 & 2 & 3 & 0 & 5 & 0 \\
Sempre a mesma iluminação & 5 & 3 & 3 & 0 & 0 & 0 \\
Durar bastante & 6 & 5 & 0 & 0 & 0 & 0 \\
Não estourar & 10 & 0 & 0 & 3 & 0 & 3 \\
Não dar choque & 10 & 0 & 0 & 2 & 0 & 5 \\
\hline Importância & & $\mathbf{1 5 3}$ & $\mathbf{1 0 4}$ & $\mathbf{7 4}$ & $\mathbf{1 1 7}$ & $\mathbf{1 0 4}$ \\
Importância \% & & $\mathbf{2 8 \%}$ & $\mathbf{1 9 \%}$ & $\mathbf{1 3 \%}$ & $\mathbf{2 1 \%}$ & $\mathbf{1 9 \%}$ \\
Importância relativa & $\mathbf{1 0}$ & $\mathbf{7}$ & $\mathbf{5}$ & $\mathbf{8}$ & $\mathbf{7}$ \\
\hline
\end{tabular}

Omitiu-se, propositalmente, em todo o exemplo, a linha destinada às especificações ("quanto") para as matrizes de $Q F D$, pois essa determinação não é didaticamente relevante, apesar de indispensável na prática. A importância de cada um dos requisitos é calculada pelo somatório dos produtos dos pesos de cada expectativa vs. a nota (índice) dada à intensidade desta correlação. Exemplo: a importância do requisito "bulbo resistente" é igual a (peso da expectativa "baixo custo" (8) x nota da correlação entre eles (3) + peso da expectativa de "não estourar" (10) x peso da correlação entre eles (3) + peso da expectativa de "não dar choque" $(10) \times$ peso da correlação entre eles (2)) $8 \times 3+10 \times 3+10 \times 2=74$.

A "importância \%" é calculada pela divisão da importância de cada requisito pelo somatório de todas as importâncias. A importância relativa, por sua vez, é calculada por uma regra de três, na qual o valor da importância correspondente à importância relativa procurada é multiplicado pelo maior peso possível (10), dividido pela maior importância observada (153). Exemplo: para a importância 104, a importância relativa é (104 x 10) / 153, ou seja, 7. A importância relativa faz com que os "resultados" dos requisitos ("pesos relativos") fiquem na mesma escala dos pesos das expectativas. Deve-se atentar para o fato de que a tabela de severidades não é válida para a importância relativa dos requisitos, somente é válida para pontuar o peso das expectativas.

A próxima etapa (2) consiste na identificação e avaliação, com FMEA, dos modos de falha para cada uma das expectativas. Em seguida (etapa 3), estabelecem-se as causas para os modos de falha, classificando-se a ocorrência e a detecção de cada um. Para isso, adotam-se os índices e critérios do manual de FMEA da norma QS 9000 (Chrysler et al., 1998), apresentados nas Tabelas 5 e 6.

Na Tabela 7, apresentam-se dois modos de falha para o exemplo da lâmpada conforme a abordagem original
Tabela 5. Tabela para avaliação da ocorrência

\begin{tabular}{llc}
\hline $\begin{array}{c}\text { Probabilidade de } \\
\text { ocorrência }\end{array}$ & \multicolumn{1}{c}{ Critério } & Ocorrência \\
\hline Muito alta: Ocorrência & $>1 \mathrm{em} 2$ & 10 \\
quase invitável & $1 \mathrm{em} 3$ & 9 \\
Alta: Ocorrências & $1 \mathrm{em} 8$ & 8 \\
freqüientes & $1 \mathrm{em} 20$ & 7 \\
Moderada: Ocorrências & $1 \mathrm{em} 80$ & 6 \\
ocasionais & $1 \mathrm{em} 400$ & 5 \\
& $1 \mathrm{em} 2.000$ & 4 \\
Baixa: Poucas ocorrências & $1 \mathrm{em} 15.000$ & 3 \\
& $1 \mathrm{em} 150.000$ & 2 \\
Remota: Falha é improvável & $<1 \mathrm{em} 1.500 .000$ & 1 \\
\hline
\end{tabular}

de FMEA. Escolheram-se duas expectativas para exemplificação: "baixo custo" e "iluminação agradável", cujas severidades determinadas pelo método original (sem ligação com $Q F D$ ), são 6 e 8, respectivamente. No método proposto, como se verá adiante, as severidades não serão estas. Serão os pesos apontados na primeira matriz $Q F D$, 8 e 7 , respectivamente.

No método proposto, a Tabela 6 será rearranjada na forma de uma árvore (Figura 9). Na Tabela 4, observa-se que os efeitos não são descritos. Isto não é necessário, pois a severidade da falha é indicada diretamente pelo peso da expectativa contido na primeira matriz $Q F D$ (Tabela 4). A severidade (S) vem conjugada à necessidade/ requisito de $Q F D$ (neste caso necessidade) num símbolo predefinido conforme a legenda.

Em cada desenvolvimento de FMEA é importante indicar seu "momento" de aplicação. Neste caso, conforme a Figura 9, "FMEA das expectativas do cliente". Das necessidades/requisitos ramificam-se as medidas concluídas (ou a serem tomadas) na detecção (conjugadas ao índice "D") e os modos de falhas. Dos modos de falhas 
saem as causas conjugadas ao índice de ocorrência "O", de cada falha. Medidas a serem tomadas na detecção ou na ocorrência (etapa 4), são exibidas em símbolos prede-

Tabela 6. Tabela para avaliação da detecção.

\begin{tabular}{|c|c|c|}
\hline $\begin{array}{c}\text { Probabilidade } \\
\text { de detecção }\end{array}$ & Critério & Detecção \\
\hline Quase impossível & $\begin{array}{l}\text { Não conhecido controle disponí- } \\
\text { vel para detectar o modo falha }\end{array}$ & 10 \\
\hline Muito remota & $\begin{array}{l}\text { Probabilidade muito remota de } \\
\text { que o controle atual irá detectar } \\
\text { o modo de falha }\end{array}$ & 9 \\
\hline Remota & $\begin{array}{l}\text { Probabilidade remota de que } \\
\text { o controle atual irá detectar o } \\
\text { modo de falha }\end{array}$ & 8 \\
\hline Muito baixa & $\begin{array}{l}\text { Probabilidade muito baixa de } \\
\text { que o controle atual irá detectar } \\
\text { o modo de falha }\end{array}$ & 7 \\
\hline Baixa & $\begin{array}{l}\text { Probabilidade baixa de que o } \\
\text { controle atual irá detectar o } \\
\text { modo de falha }\end{array}$ & 6 \\
\hline Moderada & $\begin{array}{l}\text { Probabilidade moderada de que } \\
\text { o controle atual irá detectar o } \\
\text { modo de falha }\end{array}$ & 5 \\
\hline $\begin{array}{l}\text { Moderadamente } \\
\text { alta }\end{array}$ & $\begin{array}{l}\text { Probabilidade moderadamente } \\
\text { alta de que o controle atual irá } \\
\text { detectar o modo de falha }\end{array}$ & 4 \\
\hline Alta & $\begin{array}{l}\text { Probabilidade alta de que o con- } \\
\text { trole atual irá detectar o modo de } \\
\text { falha }\end{array}$ & 3 \\
\hline Muito Alta & $\begin{array}{l}\text { Probabilidade muito alta de que } \\
\text { o controle atual irá detectar o } \\
\text { modo de falha }\end{array}$ & 2 \\
\hline Quase certamente & $\begin{array}{l}\text { Controle atual quase certamente } \\
\text { irá detectar o modo de falha }\end{array}$ & 1 \\
\hline
\end{tabular}

finidos como medida concluída ou medida planejada. As medidas planejadas serão sempre posicionadas abaixo das medidas concluídas.

Para o cálculo do risco, o índice de ocorrência utilizado será aquele conjugado inicialmente à causa da falha. Quando medidas planejadas na ocorrência são concluídas, o índice de ocorrência passa a ser este índice conjugado à medida implantada. $\mathrm{O}$ mesmo vale para o índice de detecção. Deste modo, o risco (R) de não atendimento da expectativa é calculado por $\mathrm{R}=\mathrm{S} \times \mathrm{D} \times \mathrm{O}$. Por exemplo, o risco 96, correspondente à expectativa "baixo custo", é $\mathrm{R}=8(\mathrm{~S}) \times 3(\mathrm{D}) \times 4(\mathrm{O})=96$. O risco futuro, caso a medida planejada na ocorrência seja implantada, pode ser previsto como: $\mathrm{R}=8(\mathrm{~S}) \times 3(\mathrm{D}) \times 2(\mathrm{O})=48$ (o risco previsto não deve aparecer para evitar confusão).

$\mathrm{Na}$ expectativa "iluminação agradável”, observa-se que não existe medida de detecção implementada (não há "controle atual" para esta expectativa). Neste caso, devese assumir, implicitamente, que a detecção é nula e seu índice deverá ser $\mathrm{D}=10$. Dessa forma, o risco para "iluminação agradável” será $\mathrm{R}=7$ (S) x 10 (D) x 4 (O) = 280 .

A próxima etapa (5) consiste na identificação e avaliação dos possíveis modos de falha para cada requisito do sistema. Em seguida, vem a análise das causas (etapa 6) dos modos de falha para cada requisito, classificando-se a ocorrência (O) e a detecção (D) de cada modo de falha. A seguir, estabelecem-se as medidas na detecção e/ou na ocorrência (etapa 7). Estas etapas são análogas às etapas 2, 3 e 4, e seu desenvolvimento não será mostrado.

Dando sequiência ao método (etapa 8), desenvolve-se uma matriz de relações para transformar os requisitos do sistema em requisitos do projeto (Tabela 8). É importante aqui perceber que os pesos das necessidades (agora "requi-

Tabela 7. Exemplo de FMEA das expectativas no formulário tradicional.

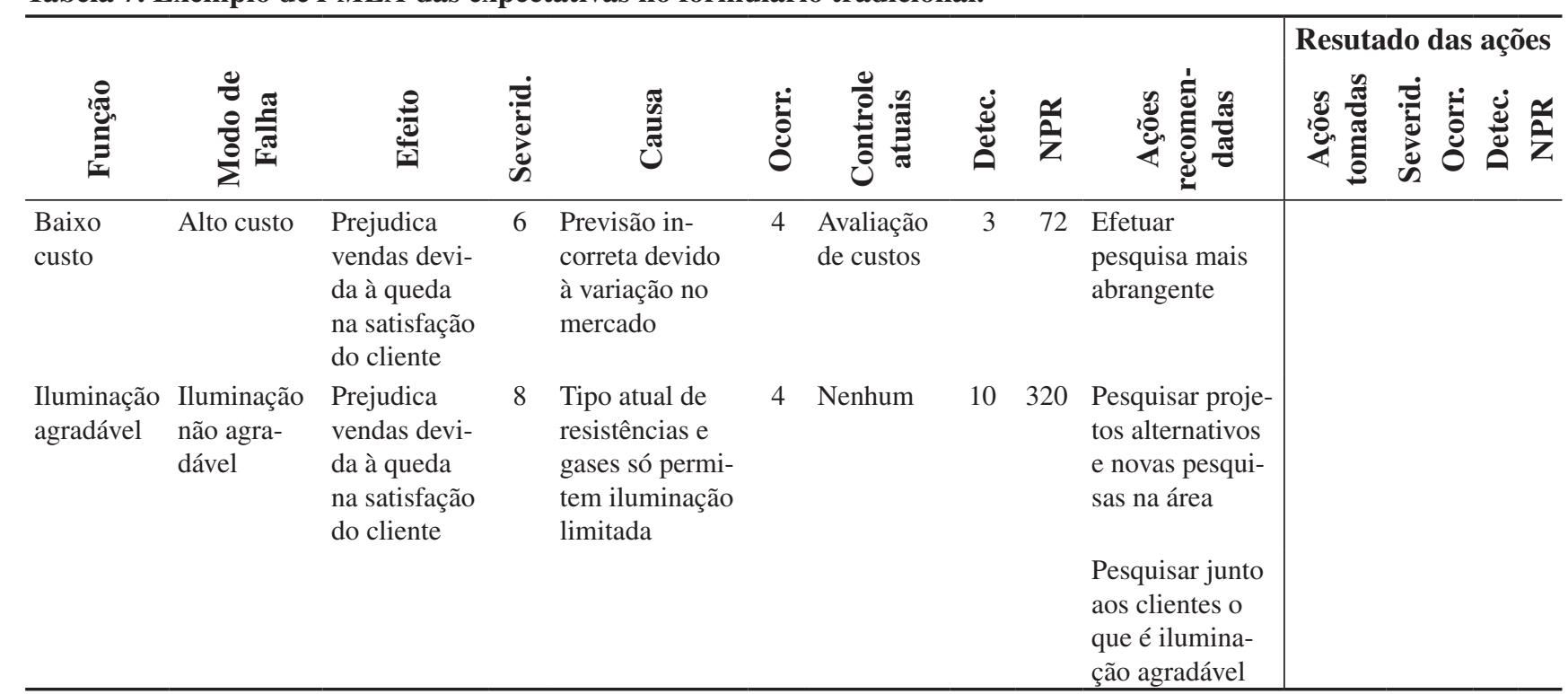




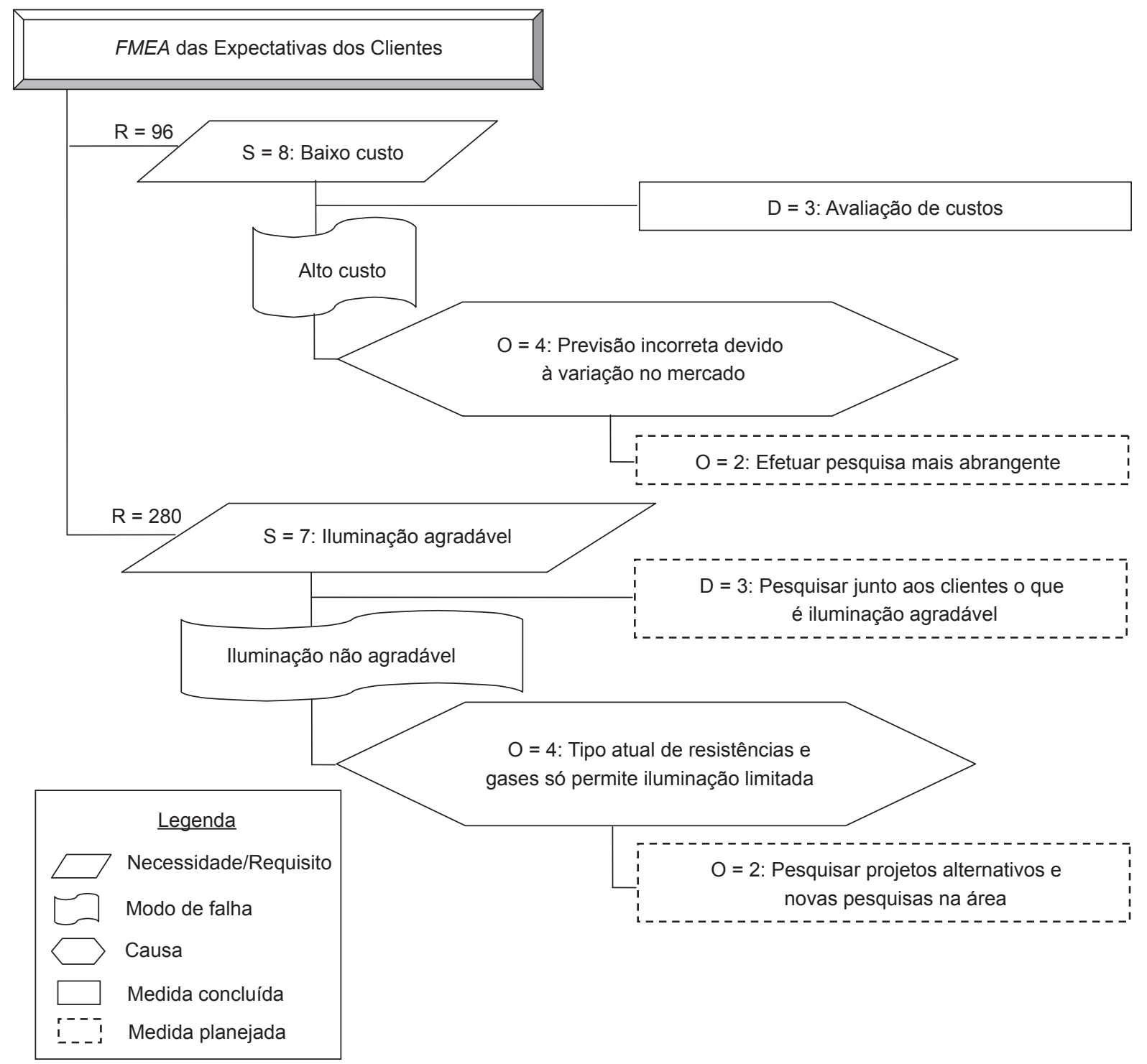

Figura 9. FMEA modificado para avaliação de riscos sobre as expectativas.

Tabela 8. Matriz de relações "Requisitos do Sistema x Requisitos do Projeto".

\begin{tabular}{|c|c|c|c|c|c|c|c|c|}
\hline \multirow[t]{2}{*}{ Necessidades } & \multirow[t]{2}{*}{ Pesos } & \multicolumn{7}{|c|}{ Requisitos } \\
\hline & & $\begin{array}{c}\text { Composição } \\
\text { da liga do } \\
\text { filamento }\end{array}$ & $\begin{array}{c}\text { Diâmetro } \\
\text { do } \\
\text { filamento }\end{array}$ & $\begin{array}{c}\text { Comprimento } \\
\text { do filamento }\end{array}$ & $\begin{array}{c}\% \\
\text { Neon no } \\
\text { gás }\end{array}$ & $\begin{array}{c}\text { Tenacidade } \\
\text { do bulbo }\end{array}$ & $\begin{array}{c}\text { Diâmetro } \\
\text { na base do } \\
\text { bulbo }\end{array}$ & $\begin{array}{c}\text { Resistência } \\
\text { à fadiga } \\
\text { na junção } \\
\text { conexão/ } \\
\text { bulbo }\end{array}$ \\
\hline $\begin{array}{l}\text { mento adequado } \\
\text { material especial }\end{array}$ & 10 & 3 & 5 & 3 & 0 & 0 & 0 & 0 \\
\hline com nova mistura & 7 & 0 & 0 & 0 & 3 & 0 & 0 & 0 \\
\hline bo resistente & 5 & 0 & 0 & 0 & 0 & 5 & 0 & 0 \\
\hline minosidade adequada & 8 & 2 & 3 & 3 & 3 & 0 & 1 & 0 \\
\hline jeto que evite riscos & 7 & 0 & 0 & 0 & 0 & 3 & 0 & 5 \\
\hline portância & & 46 & 74 & 54 & 45 & 46 & 8 & 35 \\
\hline portância \% & & $15 \%$ & $24 \%$ & $18 \%$ & $15 \%$ & $15 \%$ & $3 \%$ & $11 \%$ \\
\hline portância relativa & & 6 & 10 & 7 & 6 & 6 & 1 & 5 \\
\hline
\end{tabular}


sitos do sistema") não são mais atribuídos conforme a tabela de severidades, mas são utilizados os valores de importância relativa resultantes da primeira matriz de relações (Tabela 4). Estes valores são, pela ordem, 10, 7, 5, 8 e 7.

A próxima etapa (9) consiste na identificação e avaliação dos possíveis modos de falha, para cada requisito de projeto, seguida pela determinação das causas (etapa 10) e planejamento de medidas na detecção e/ou ocorrência (etapa 11). Apresenta-se, na Tabela 9, como poderia ser o formulário tradicional com as severidades avaliadas sem concatenação com $Q F D$ para a "composição da liga do filamento", "diâmetro do filamento" e "diâmetro da base do bulbo". Na Figura 10, apresenta-se como fica a abordagem proposta para os mesmos requisitos.

Na Figura 10, o requisito "diâmetro do filamento" exibe o nível máximo de importância relativa (10), que será a sua severidade em FMEA. Na abordagem tradicional (Tabela 9), esta severidade foi classificada com nível 8, o que poderia ser perfeitamente factível. Isto teria um impacto muito significativo, pois, na abordagem tradicional, o modo de falha "composição fora do especificado" (Tabela 9) seria considerado o modo de falha mais significativo, com severidade 8 e risco $\mathrm{R}=144$. O modo de falha "diâmetro do filamento maior" fica em segundo, com severidade 8 e $\mathrm{R}=120$. Quando se utiliza a severidade proposta (Figura 10) na nova abordagem, a situação inverte-se: a "composição da liga do filamento" fica com severidade 6 e $\mathrm{R}=108$ e o "diâmetro do filamento" com severidade 10 e $\mathrm{R}=150$. Desse modo, com a abordagem tradicional, os recursos seriam priorizados erradamente, pois é o "diâmetro do filamento" que deve receber maior atenção.

Seguindo-se o método proposto, vêm as etapas de $12 \mathrm{a}$ 19 , que não serão mostradas, pois seu desenvolvimento é análogo aos já apresentados.

\section{Conclusões}

O trabalho de integração de métodos gerenciais traz o desafio de olhar cada um dos métodos em foco e, ao mesmo tempo, entender como eles podem trabalhar de forma harmônica e integrada. Este esforço revelou que, curiosamente, $Q F D$ e FMEA, dois métodos criados originalmente para aplicações distintas e de natureza bastante diferentes, são, na verdade, altamente complementares. $\mathrm{O} Q F D$, ligado mais à "criatividade no desenvolvimento do novo", e o FMEA, calcado mais na "análise do já criado", quando integrados, revelam uma nova e poderosa "ferramenta" para a qualidade baseada na filosofia da avaliação sistemática das possibilidades de falhas de tudo o que for concebido.

A mecânica da integração proposta é bem mais complexa do que os métodos $Q F D$ e $F M E A$ isoladamente. No entanto, a proposta pode ser de valia às empresas que demandam altos níveis de qualidade final, como exem-

Tabela 9. Exemplo de FMEA de projeto no formulário tradicional.

\begin{tabular}{|c|c|c|c|c|c|c|c|c|c|c|c|c|c|c|}
\hline \multirow[b]{2}{*}{ 氖选 } & \multirow[b]{2}{*}{ 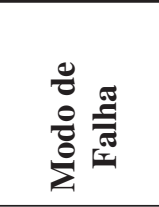 } & \multirow[b]{2}{*}{$\frac{0}{\stackrel{0}{\frac{\pi}{2}}}$} & \multirow[b]{2}{*}{ 巻 } & \multirow[b]{2}{*}{ שֶ } & \multirow[b]{2}{*}{$\stackrel{\ddot{0}}{0}$} & \multirow[b]{2}{*}{ 总 } & \multirow[b]{2}{*}{ 巳ed } & \multirow[b]{2}{*}{$\frac{\mathscr{a}}{\bar{Z}}$} & \multirow[b]{2}{*}{ 选 } & \multicolumn{5}{|c|}{ Resutado das ações } \\
\hline & & & & & & & & & & 选 & 串 & 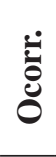 & 巳 & 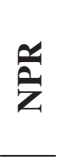 \\
\hline $\begin{array}{l}\text { Compo- } \\
\text { sição da } \\
\text { liga do } \\
\text { filamento }\end{array}$ & $\begin{array}{l}\text { Composi- } \\
\text { ção fora do } \\
\text { espec. }\end{array}$ & $\begin{array}{l}\text { Tem impacto } \\
\text { na luminosi- } \\
\text { dade durabi- } \\
\text { lidade e no } \\
\text { consumo de } \\
\text { energia }\end{array}$ & 8 & $\begin{array}{l}\text { Instabilidade da } \\
\text { matéria-prima }\end{array}$ & 3 & $\begin{array}{l}\text { Medição da } \\
\text { compo- } \\
\text { sição do } \\
\text { filamento }\end{array}$ & 6 & 144 & $\begin{array}{l}\text { Restrigir espe- } \\
\text { cificações da } \\
\text { matéria-prima }\end{array}$ & & & & & \\
\hline $\begin{array}{l}\text { Diâmetro } \\
\text { do fila- } \\
\text { mento }\end{array}$ & $\begin{array}{l}\text { Diâmetro } \\
\text { do filamen- } \\
\text { to maior }\end{array}$ & $\begin{array}{l}\text { Tem impacto } \\
\text { na luminosi- } \\
\text { dade, dura- } \\
\text { bilidade e no } \\
\text { consumo de } \\
\text { energia }\end{array}$ & 8 & $\begin{array}{l}\text { Desgaste da } \\
\text { matriz }\end{array}$ & 3 & $\begin{array}{l}\text { Medir } \\
\text { diâmetro } \\
\text { diáriamente }\end{array}$ & 5 & 120 & $\begin{array}{l}\text { Limpeza regu- } \\
\text { lar da matriz } \\
\text { e verificação } \\
\text { períodica do } \\
\text { desgaste }\end{array}$ & & & & & \\
\hline \multirow[t]{2}{*}{$\begin{array}{l}\text { Diâmetro } \\
\text { na base do } \\
\text { bulbo }\end{array}$} & $\begin{array}{l}\text { Diâmetro } \\
\text { maior }\end{array}$ & $\begin{array}{l}\text { Prejudica a } \\
\text { iluminação, } \\
\text { mas não é } \\
\text { perceptível } \\
\text { ao cliente }\end{array}$ & 1 & $\begin{array}{l}\text { Erro no ajuste } \\
\text { da sopragem }\end{array}$ & 6 & $\begin{array}{l}\text { Medição } \\
100 \% \text { do } \\
\text { diâmetro }\end{array}$ & 5 & 30 & & $\begin{array}{l}\text { Treina- } \\
\text { mento do } \\
\text { operador }\end{array}$ & & & 5 & 15 \\
\hline & & & & & & & & & $\begin{array}{l}\text { Modificar o } \\
\text { ajuste para } \\
\text { facilitar o } \\
\text { operador }\end{array}$ & & & & & \\
\hline
\end{tabular}


plo, as indústrias microeletrônica, espacial ou aeronáutica. Ou seja, o método integrado pode ser útil para fabricantes que almejam e acreditam que o "zero defeito" seja realmente uma meta factível e estejam dispostos a arcar com o esforço e os custos da implantação. Este é um ponto de destaque, já que $Q F D$ e $F M E A$, afirmam

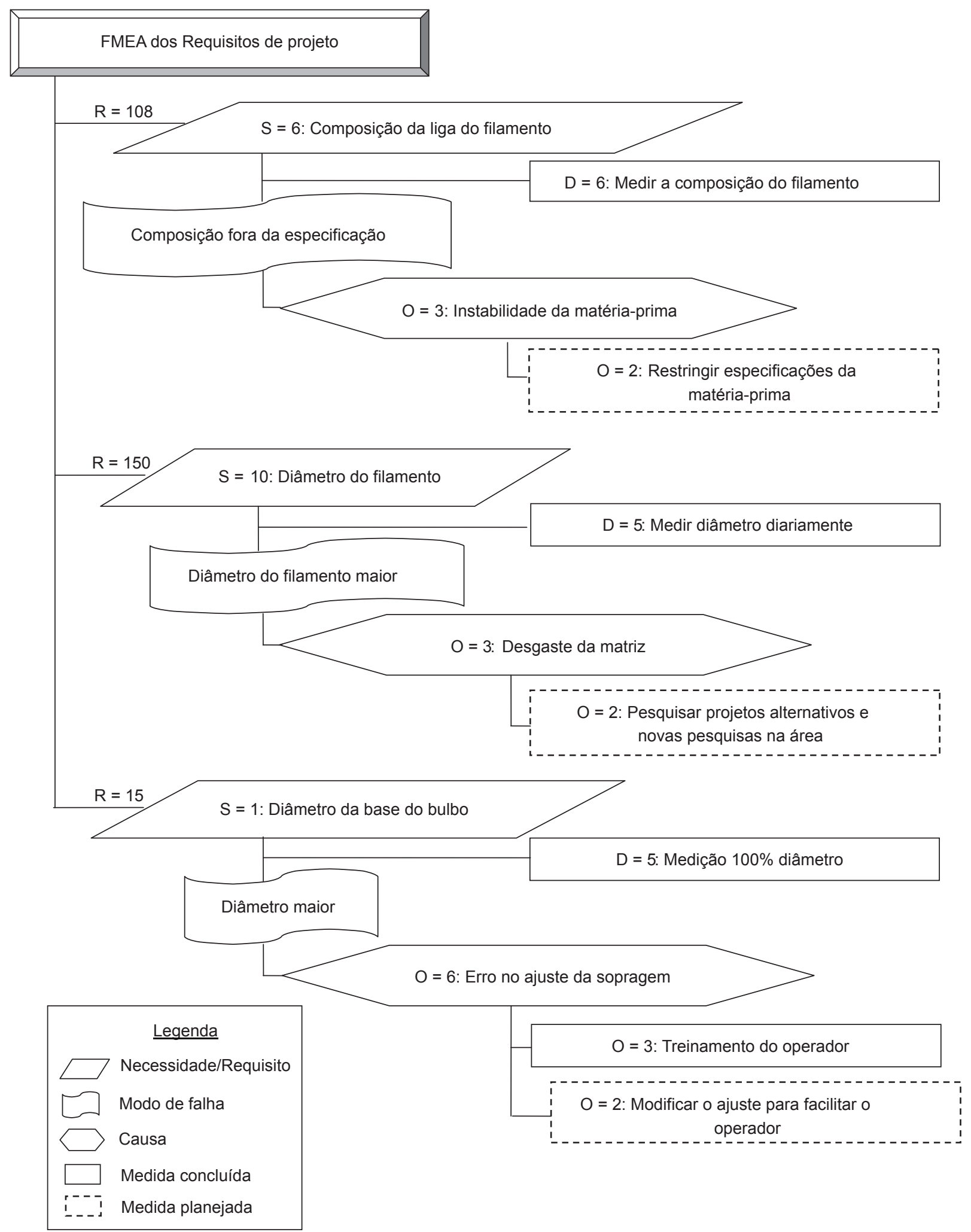

Figura 10. FMEA modificado para avaliação de riscos sobre os requisitos de projeto. 
Vollert Jr. (1996) e Alcântara (2003), são métodos que demandam muito tempo e altos custos para implantação, pois requerem um programa extenso de implementação, envolvendo a conscientização das pessoas, decisões operacionais, estruturação das equipes, coordenadores e facilitadores, treinamento, equipamentos para informação, entre outros. Desse modo, a integração proposta demandaria provavelmente mais tempo e maiores custos de implantação.

O que é importante ressaltar é que a integração $Q F D /$ FMEA normalmente utilizada não contempla suas melhores possibilidades. Na aplicação $Q F D / F M E A$ tradicional, todos os ciclos de $Q F D$ não são avaliados por $F M E A$. Além disso, a aplicação tradicional é fraca, pois os requisitos e necessidades de $Q F D$ (na sua primeira fase de aplicação) não são correlacionados juntamente com FMEA. Dessa forma, não é possível mensurar qual o risco total que uma falha qualquer traz sobre um requisito ou necessidade em termos de "não atendimento de uma expectativa do cliente". Ou seja, na abordagem tradicional, não se tem uma medida do impacto que uma falha, que possa ocorrer no processo de produção, no projeto ou no conceito do sistema, possa ter sobre os requisitos ou expectativas do cliente.

No método aqui proposto, estas fraquezas são eliminadas. As falhas são avaliadas já no primeiro ciclo de $Q F D$, a partir das próprias expectativas declaradas, e avançam sobre os requisitos até o último ciclo de desdobramentos. Além disso, a priorização dos requisitos em relação às expectativas dos clientes fornecidas por $Q F D$, quando utilizada como base para a pontuação da severidade em FMEA, torna a avaliação dos riscos um indicador muito mais fiel do "não atendimento" das expectativas do que somente a simples avaliação baseada na experiência do "time" a partir de uma tabela de referência. Dessa forma, FMEA passa a ter seus modos de falha ligados diretamente ou indiretamente às necessidades e aos requisitos de $Q F D$.

Na formulação para $F M E A$ proposta, a apresentação gráfica em forma de árvore facilita as atualizações e a visualização do status do risco e das medidas planejadas e concluídas. Imagina-se, porém, que a aplicação computacional desse formato proposto é que viabilizaria definitivamente sua operacionalização, dado que, neste arranjo, uma tabela não pode ser previamente construída, pois todos os símbolos devem ser inseridos um a um, o que demandaria um trabalho manual considerável. Esta seria uma indicação para trabalhos futuros, assim como o desenvolvimento da integração do método proposto com outras ferramentas e métodos, criando-se uma nova "rede" de métodos "reprojetados".

O método proposto não foi pensado para ambientes de prestação de serviços. Porém, uma análise dos requerimentos destes tipos de sistemas revela ser perfeitamente possível esta aplicação. Imagina-se que para serviços que demandem baixos níveis de falhas como, por exemplo, em serviços médicos, a integração proposta possa ser válida.

\section{Referências Bibliográficas}

AKAO, Y. Quality function deployment: integrating customer requirements into product design. Cambridge, Mass: Productivity Press, 1990. 387 p.

ALCÂNTARA, J. R. Identificação do uso de QFD no desenvolvimento de produtos no Estado do Paraná. 2003. 153 p. Dissertação(Mestrado em Tecnologia) - Programa de Pós-Graduação em Tecnologia do Centro Federal de Educação Tecnológica do Paraná, Centro Federal de Educação Tecnológica do Paraná, Curitiba.

BERK, J; BERK, S. Administração da qualidade total: o aperfeiçoamento contínuo. São Paulo: IBRASA, 1997. $285 \mathrm{p}$.

CERVO, A. L.; BERVIAN, P A. Metodologia científica. 5. ed. São Paulo: Prentice Hall, 2002. 242 p.

CHRYSLER CORPORATION; FORD MOTOR COMPANY; GENERAL MOTORS CORPORATION. Requisitos do Sistema da Qualidade QS-9000. São Paulo: IQA - Instituto da Qualidade Automotiva, 1998. 112 p.
ECSS-Q-30-02A Failure mode, effects and criticality analysis (FMECA). ECSS Secretariat - ESA - Publication Division. Disponível em: <http://www.estec.esa.nl/ ecss/admin/download/q/ecss-q-30-02a.pdf >. Acesso em: 11 maio 2005.

FERNANDES, J. M. Uma proposta de integração entre métodos para o planejamento e controle da qualidade baseada no FMEA. 2005. 145 p. Dissertação (Mestrado em Engenharia de Produção e Sistemas) - Programa de Pós-Graduação em Engenharia de Produção e Sistemas, Pontifícia Universidade Católica do Paraná, Curitiba.

GILCHRIST, W. Modeling failure modes and effects analysis. International Journal of Quality \& Reliability Management, Bradford, v. 10, n. 5, p. 16-24, 1993.

GINN, D. M.; JONES, D. V.; RAHNEJAT, H.;ZAIRI, M. The QFD/FMEA interface. European Journal of Innovation Management, Bradford, v. 1, n. 1, p. 7-20, 1998.

GUAZZI, D. M. Utilização do QFD como ferramenta de melhoria contínua do grau de satisfação de clientes 
internos: uma aplicação em cooperativas agropecuárias. 1999. 226 p. Tese (Doutorado em Engenharia de Produção) - Programa de Pós-Graduação em Engenharia de Produção, Universidade Federal de Santa Catarina, Florianópolis.

HELMAN, H; ANDERY, P. R. P. Análise de falhas: aplicação dos métodos FMEA e FTA. Belo Horizonte: Fundação Christiano Ottoni, 1995. 156 p.

KELLER, C. W. QOS: a simple method for a big or small. Quality Progress, Milwaukee, v. 36, n. 9, p. 28-39, 2003.

LAYZELL, J; LEDBETTER, S. FMEA applied to cladding systems: reducing the risk of failure. Building Research \& Information, London, v. 26, n. 6, p. 351-357, 1998.

LIN, C. C. QFD: planejamento da qualidade. Belo Horizonte: Fundação Christiano Ottoni, 1995. 261 p.

MIL-STD-1669A Military standards procedures for performimg a failure mode, effects and criticality analysis. United States of America: Departament of Defense - USA Disponível em: <http://www.weibull.com./knowledge/milhdbk.htm>. Acessado em: 18 maio 2005.

PALADY, P. FMEA: Análise de Modos de Falhas e Efeitos: Prevendo e Prevenindo problemas antes que ocorram. São Paulo: IMAM, 1997. 270 p.
PINTO, A. K.; XAVIER, J. A. N. Manutenção: função estratégica. Rio de Janeiro: Qualitymark, 2001. 341 p.

PUENTE, J.; PINO, R.; PRIORE, P.; FOUENTE, D de L. A decision support system for applying failure mode and effects analysis. International Journal of Quality \& Reliability Management, Bradford, v. 19, n. 2, p. 137151, 2002.

STAMATIS, D. H. Failure Mode and Effect Analysis: FMEA from theory to execution. 2. ed. ASQC, Milwaukee: Quality Press, 2003. 494 p.

SULLIVAN, L. P. Quality Function Deployment. Quality Progress. Milwaukee, v. 19, n. 6, p. 39-51, 1986.

TERNINKO, J. Step-by-step QFD: customer-driven product design. Boca Raton, Florida: CRC Press, 1997. $224 \mathrm{p}$.

VOLLERT JR., J. R. Confiabilidade e falhas de campo: um estudo de caso pra melhoria da confiabilidade de um produto e do reparo através de um procedimento sistemático de coleta de dados. 1996. 128 p. Dissertação (Mestrado em Engenharia de Produção) - Programa de PósGraduação em Engenharia de Produção, Universidade Federal de Santa Catarina, Florianópolis.

\title{
PROPOSAL OF A METHOD TO INTEGRATE QFD AND FMEA
}

\author{
Abstract \\ Two quality-planning methods are recognized worldwide today for their usefulness and successful implementation: \\ QFD (Quality Function Deployment) in product and process development, and FMEA (Failure Mode and Effects \\ Analysis) in failure analysis. However, these methods are often seen as non-interrelated tools and, in practice, their \\ integration has traditionally been insufficiently and poorly exploited. This article therefore proposes a method for \\ integrating QFD and FMEA. The proposed approach presents changes in these two quality-planning methods, which \\ aim to increase the effectiveness of their integration and to confer greater clarity on their presentation. The proposed \\ method is illustrated through a fictitious example of application.
}

Keywords: QFD (Quality Function Deployment), FMEA (Failure Mode and Effects Analysis), QFD/FMEA integration method. 
